\title{
Design of a Two-Component Force Measurement System and Its Application in a Wind Tunnel
}

\author{
Mehmet E Caliskan \\ Uludag University: Bursa Uludag Universitesi \\ Muhammet U Sabirli \\ Uludag University: Bursa Uludag Universitesi \\ Irfan Karagoz ( $\sim$ karagoz@uludag.edu.tr)
}

Uludag University: Bursa Uludag Universitesi https://orcid.org/0000-0002-7442-2746

\section{Research Article}

Keywords: experimental techniques, measurement system, force measurement, lift force, drag force

Posted Date: February 22nd, 2022

DOI: https://doi.org/10.21203/rs.3.rs-1355804/v1

License: (1) This work is licensed under a Creative Commons Attribution 4.0 International License. Read Full License 


\section{Abstract}

Measuring the force components on an object simultaneously is one of the problems encountered in engineering. The design of a measurement system that can simultaneously measure such forces, as well as its working principles, production stages and application of this system in a wind tunnel are presented. The system consists of an arm to which the model is attached, a five-bar mechanism, and load cells that measure horizontal and vertical forces. The signals obtained from the load cells are amplified and transferred to a computer. Manufacture of the parts, assembly and calibration of the system are explained. An application of the measurement system was carried out in a wind tunnel and the results are presented.

\section{Introduction}

Measurement has an important place in experimental studies, design, and production stages in all engineering areas. The need to measure all physical quantities such as length, time, pressure, temperature, velocity, acceleration, mass, etc. is encountered in these studies. The second important issue is that these quantities must be measured with acceptable precision. Technological developments provide facilities and opportunities for measuring these parameters with the desired accuracy.

One of the physical quantities that need to be measured is the force which is a vector quantity. It is an important issue to measure two components of a force at the same time, as it gives both the magnitude and the direction of the force. Measurement of forces on submerged bodies is one of the best examples in engineering. Various methods such as force balance or pressure-based systems have been developed and used to measure hydrodynamic forces on a body in a flow, aerodynamic forces on an airfoil, etc.

Aerodynamic performance parameters for airfoils are $F_{L}$ (Lift force), $F_{D}$ (Drag force), and Pitching moment. Usually, aerodynamic performance measurement systems for airfoils rely on using pressure systems, force-balance systems or a combination of both.

Mueller (2000) studied aerodynamic parameters at low Reynolds numbers for fixed-wing micro-aircraft by using a force-balance system. An external weight providing stability is placed at the top of the test section of the wind tunnel. With this balance, lifting and drag forces are transmitted directly to the moment sensor. McGhee et al. (1988) used pressure distribution which is a different method than the force-balance system while measuring the aerodynamic properties of the Eppler387 airfoil. The aerodynamic forces were obtained from the measurement of the surface pressure on the airfoil

Maughmer and Bramesfeld (2008) experimentally investigated the Gurney flap effect on an airfoil and performed aerodynamic performance measurements by utilizing combinations of force-balance and pressure differential systems. They stated in their studies that the use of surface pressure integration in addition to the force-balance system had a positive effect on the obtained data. 
More examples of force-balance based systems used in measuring aerodynamic performances are also available in the literature. Michael S. Selig et al. (2911) adopted a force balance approach to obtain lift and moment data for more than 200 airfoils. Sahin and Acar also used a two-component force-balance system to measure the lift and drag forces of NACA 0015. These systems can be expanded to systems that will allow the measurement of more components. Yilmaz et al. (2016) measured pitching moment in addition to lift and drag forces using a 3-component system to measure the aerodynamic performance of wind turbine blades. on the other hand, Li et al. (2009) used a six-component force measurement system based on strain gauge balance for the investigation of the aerodynamic performances of a 1:20 scale aircraft model. Liu et al. (2019) designed a suspension force measurement system for hypersonic wind tunnel testing. Unlike conventional force-balance, the suspension force measurement system is intended not to occupy the interior space of the test section.

In this study, a force balance system that can simultaneously measure two force components on an object with load cells is presented. This system, which is designed in a modular manner, allows the change of load cells, and provides force measurement at desired intervals and precision. Additionally, the detachable model fasteners allow different wings or objects to be connected to the system. The design and manufacturing stages as well as signal processing have been introduced. The performance of the system has been discussed by using the produced measurement system to measure the lift and drag forces on a body.

\section{Design And Production Of The System}

Basically, this study aimed to design a two-component system to measure simultaneously the force components acting on an object, as in the case of aerodynamic forces on a body. As in the example of the force on a wing seen in Fig. 1, by measuring the horizontal (drag) and vertical (lift) forces on the wing, one can obtain both the magnitude $(F)$ and the direction $(\theta)$ of the force.

The measurement system consists of an arm to which the object is attached, a five-bar linkage, and load cells containing strain-gages (Fig. 2). This mechanism is made of thin aluminum rectangular profiles with $5 \star 20 \mathrm{~mm}$ cross-section and bearings are used at the connection points to reduce friction. Therefore, the rods can rotate freely around the joints. In addition, buttresses are used to fix the load cells and stationary joints of the five-bar mechanism to the stand. The buttresses were made from aluminum sigma profile with $25 \mathrm{~mm}$ size. The five-bar mechanism is integrated into the system for force transmission in the $\mathrm{x}$ and y directions. For absolute balance, double elements are used in the horizontal bars, and also balance weight was positioned on top of one of these horizontal bars.

Bolts are attached to the load cells to transmit the load at an angle of 90 degrees. Thanks to the connections with ball bearings, the forces in the $x$ and $y$ directions are properly transmitted to the load cells independently of each other. As can be seen, while the system is operating, due to the lift force on the body in the vertical direction, the bar- 1 which the body is attached, moves in the $y$-direction and forces the bar-3 to rotate about the fixed joint. The bar-3 creates a strain on the load cell and thus the lift force is 
measured. In the case of force on the body in the x-direction, the force is transmitted from the number bar 1 to the bar-4 through the bar-2. Thus, the force in the $x$-direction in the bar- 4 is transmitted to the other load cell that measures the drag force. All system components are designed and manufactured. The system with supports and movable bars is mounted on a stand made of aluminum sigma profiles to maintain stability. It has been also ensured that the loads on the load cells are only lift and drag forces.

The system is suitable for accurately measuring the vertical and horizontal forces exerted on bodies such as bluff bodies, airfoils, symmetric or asymmetric, bionic wing structures. This design always transfers the forces coming on it to the load cells.

The electronic equipment including HX711amplifier were used to amplify the signals from the load cells and transfer them to the computer. 2 load cells are used in the system which aims to measure the force with strain gauges. Arduino Uno is used as the controller in the system. Required electrical power is supplied by a $5 \mathrm{~V}, 2 \mathrm{~A}$ power supply. Other electronic parts integrated into the system are PCB circuit board, 220 ohm resistor, button, and wires.

$10 \mathrm{~Hz}$ data is obtained separately from the load cells. Two programs have been written to process this data. The first of these enables the measured signal to be converted into a force unit of newton. For this purpose, a calibration study was carried out and multiplier factors were determined for horizontal and vertical forces. The software that performs this process is given in Appendix-A.

The second program is the main software, and the recorded data can be processed as desired and statistical information can be obtained by this software. The multiplier factors determined separately for lift and drag forces were also inserted in the main software. The prepared software is given in AppendixB. This software averages the data collected at $10 \mathrm{~Hz}$ frequency over a short period of 2 minutes for both lift and drag forces. The unit of the output data is $\mathrm{mN}$.

These forces are made dimensionless by dividing them by the dynamic force, as in Eqs. 1 and 2. That is the lift and drag coefficients can be written as

$$
C_{L}=\frac{F_{L}}{0,5 * \rho * u^{2} * A}
$$

1

$$
C_{D}=\frac{F_{D}}{0,5 * \rho * u^{2} * A}
$$

respectively. Where, $\rho$ is the density of air, $u$ is the velocity of air, and $A$ is the projection area of the model. Thus, the calculation was made by taking the average of approximately 1200 data in total for each force measurement given as a result. 


\section{Experiments}

Lift and drag forces on a NACA airfoil model were measured in a wind tunnel by using the presented measurement device to test the system. The air tunnel is an open circuit type air tunnel that has a $700 \star 600 \mathrm{~mm}$ rectangular cross-section, with a test area of $2 \mathrm{~m}$ long. Air velocity of $30 \mathrm{~m} / \mathrm{s}$ can be achieved in this tunnel. The positioning of the aerodynamic measuring system and model in this tunnel is shown in Fig. 3.

Before starting the experiments, calibration of the system was carried out and multiplier factors were determined for the forces to obtain accurate data from the system. These measurements and factor settings were made separately for both lift and drag forces. Scale weights with known masses are used as reference weights. Reference weights for lift forces were put on the Y-shaped arm to which the wing is connected, and factor adjustment was made from the software to obtain correct data. Similar adjustment for the drag force was performed by pulling the wing in the x-direction by means of the weight hanging on the rope passed over a bearing.

Since a part of the supporting system remains in the tunnel, the force on this part will also be included in the measurements. Although this is small compering to the force exerted on the model due to symmetry and small area, the lift and drag forces created by this part should be considered for high precision on measuring force on the model. Therefore, the aerodynamic forces on this part were determined in preliminary tests without the wing at each wind speed in the tunnel.

A typical example of the force data recorded throughout the experiments is shown in Fig. 4, at $10 \mathrm{~m} / \mathrm{s}$ air velocity. The average drag force measured using this data was calculated as $347.74 \mathrm{mN}$ with a standard deviation of $1.24 \mathrm{mN}$, an average lift force of $126.41 \mathrm{mN}$ and a standard deviation of $2.65 \mathrm{mN}$.

\section{Results And Discussion}

After the calibration studies, the lift and drag coefficients of a NACA0015 model were measured at 4 different velocities $(5,7,10,12 \mathrm{~m} / \mathrm{s})$ and 13 different attack angles $(-15,-12,-10,-8,-5,-3,0,3,5,8,10,12$, 15). The variation of the lift and drag coefficients with respect to attack angles (a) at 5 and $12 \mathrm{~m} / \mathrm{s}(\mathrm{Re}=$ 22000 and 67000, respectively) are given in Fig. 5. While the drag coefficient increases with the angle of attack, the lift coefficient increases up to a certain angle and then decreases. This is an expected situation and is in accordance with the literature.

The change of $C_{L} / C_{D}$ ratio as aerodynamic performance for a wing is important and also indicates the angle of attack where the ratio is maximum. This ratio has been obtained from the experimental results. The maximum ratio is around 5 degrees for $\operatorname{Re}=22000$, while it occurs around 8 degrees for $\operatorname{Re}=67000$.

In such wind tunnel measurement systems, vibrations may occur due to different reasons and may reduce the accuracy of measurements. It has not been observed that the linkage structure in the designed system exhibits its own resonances that may be excited by the fluid flow. However, flow-induced 
vibrations can be expected in certain conditions, due to the nature of the flow. Such vibrations detected by the measurement system can also be analysed by processing the obtained data (Fallenius et al., 2019).

\section{Conclusions}

The design of a two-component force measurement system is presented. The designed modular system allows the connection of load cells that can measure force at different ranges and precision, as well as allowing different airfoils or objects to be installed in the system as a model.

The hardware and software components used in the measurement system, as well as the calibration of the device were introduced. Performance parameters of a symmetric NACA airfoil were obtained in a wind tunnel using the measuring device developed as an application example.

The experimental results obtained from the system showed that the aerodynamic performance curves obtained are consistent with the results obtained in the literature. This gives us important clues about the proper functioning of the system.

Since precise measurements are required in the system, the production of the system with advanced and precise production methods will increase the accuracy of the data obtained.

\section{Declarations}

Conflicts of Interest: As the authors of this manuscript, we have no conflict of interest to declare.

\section{References}

1. Fallenius BEG et al (2019) Assessment of Wall Vibrations in the Long Pipe Facility at CICLoPE. In: Örlü R., Talamelli A., Peinke J., Oberlack M. (eds) Progress in Turbulence VIII. iTi 2018. Springer Proceedings in Physics, vol 226. Springer, Cham. https://doi.org/10.1007/978-3-030-22196-6_32

2. Li Y, Ding X, Wang Y (2009) Force measurement system of a low-speed wind tunnel. In:2009 9th International Conference on Electronic Measurement \& Instruments. IEEE. p. 3-302-3-305

3. Liu B, Li S, Gao H, Daim Z, Hong X (2019) Suspension force measuring system for hypersonic wind tunnel test: Design and tests. Measurement 143:226-233

4. Maughmer MD, Bramesfeld G (2008) Experimental investigation of Gurney flaps. J Aircr 45(6):20622067

5. McGhee RJ, Betty S, Walker BS, Millard BF (1988) Experimental results for the Eppler 387 airfoil at low Reynolds numbers in the Langley low-turbulence pressure tunnel. National Aeronautics and Space Administration, Scientific and Technical Information Division. NASA TM 4062

6. Mueller TJ (2000) Aerodynamic measurements at low Reynolds numbers for fixed wing micro-air vehicles. Dept of Aerospace and Mechanical Engineering, Notre Dame Univ., DTIC ADP010760 
7. Sahin I, Acir A (2015) Numerical and experimental investigations of lift and drag performances of NACA 0015 wind turbine airfoil. Int J Materials Mechanics and Manufacturing 3(1):22-25

8. Selig M, Deters R, Wiliamson G (2011) Wind tunnel testing airfoils at low Reynolds numbers. In:49th AIAA Aerospace Sciences Meeting including the New Horizons Forum and Aerospace Exposition. p. 875

9. Yilmaz I, Cam O, Tastan M, Karci A (2016) Experimental Investigation of Aerodynamic Performance of Different Wind Turbine Airfoils. J Polytechnic 19(4):577-584

Figures

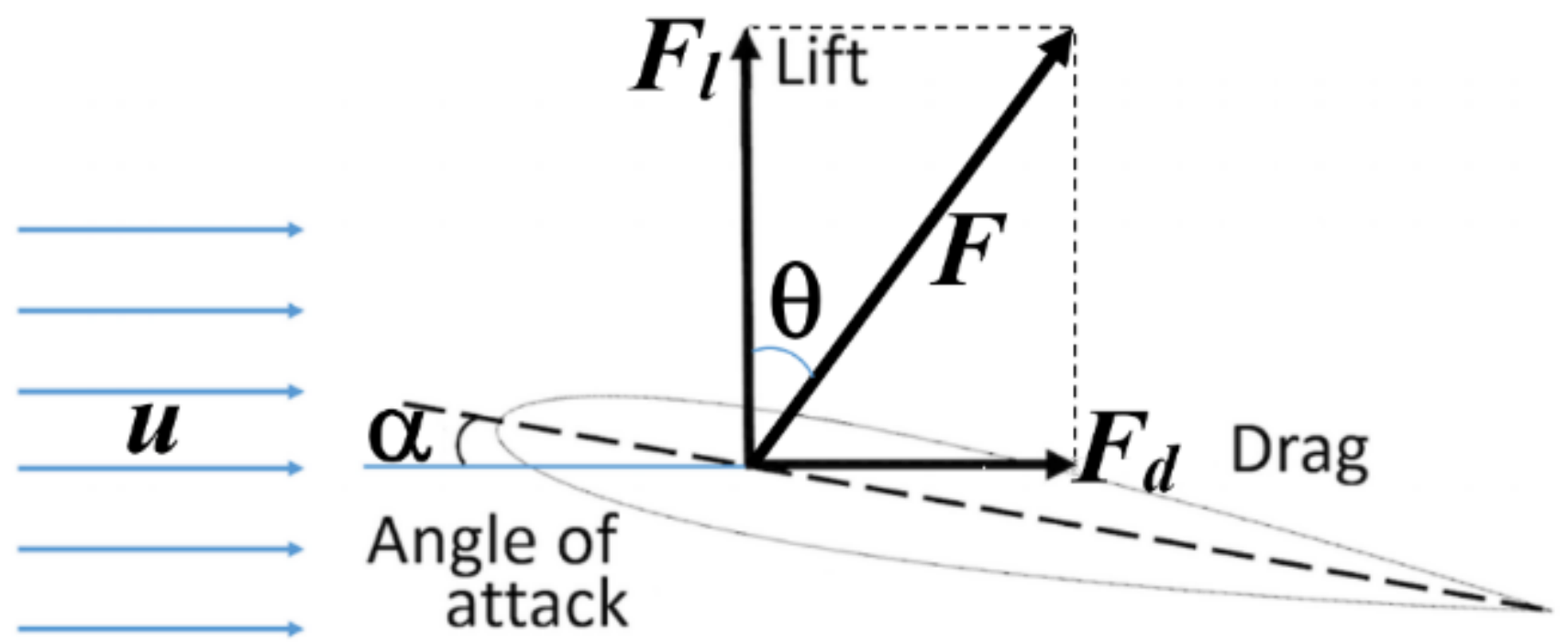

Figure 1

Lift and drag forces on an aerofoil 


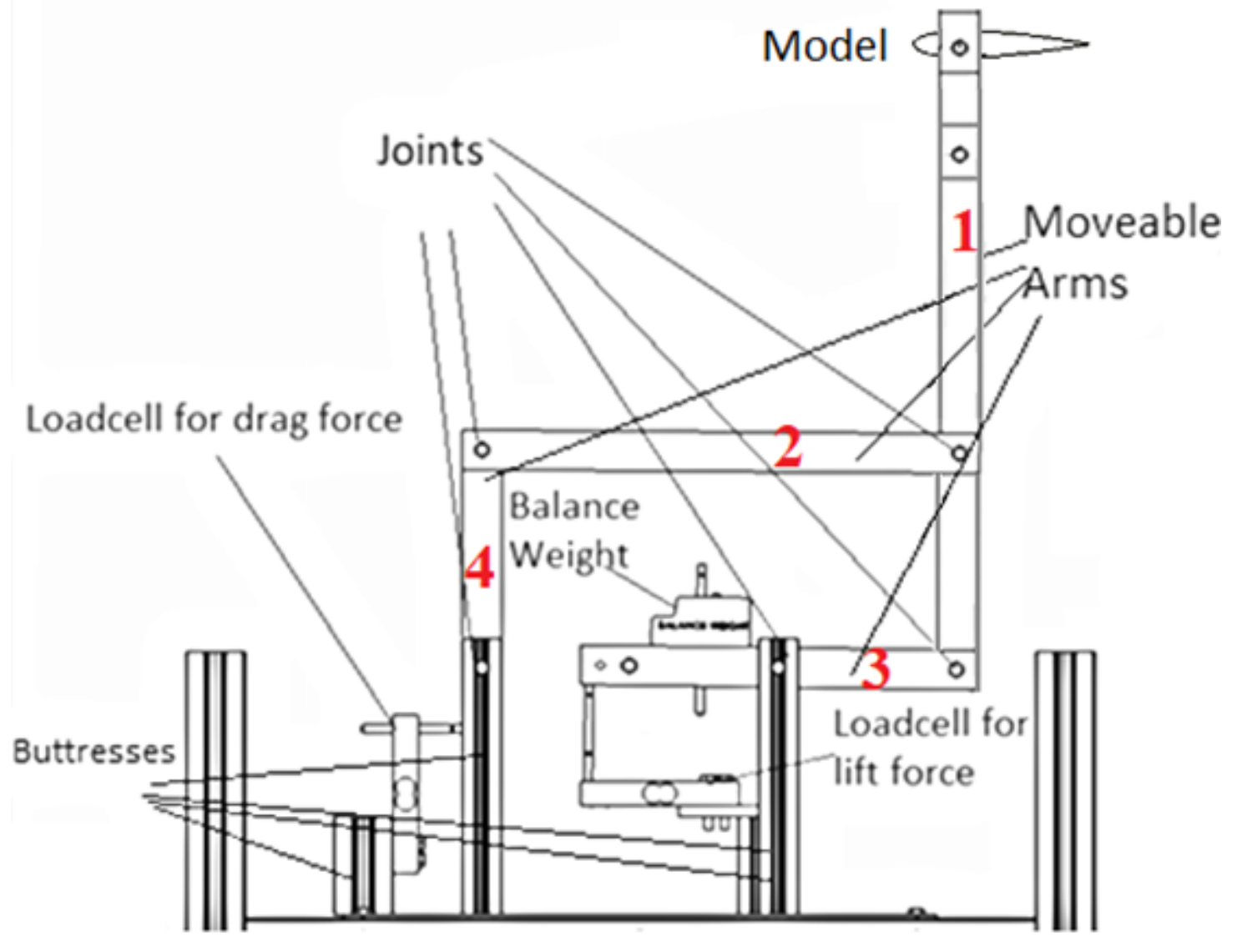

Figure 2

Joints and the other parts of the system 


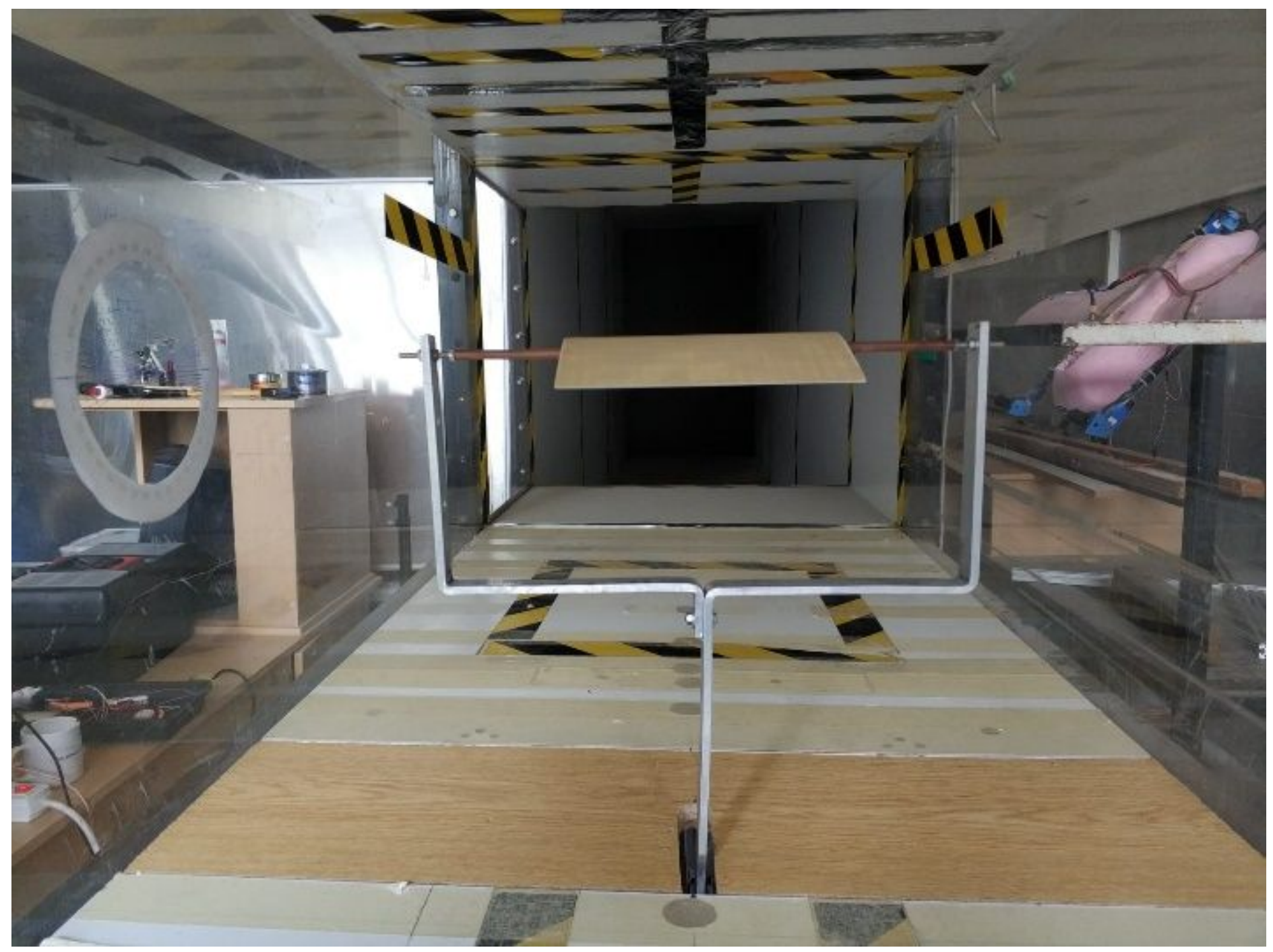

Figure 3

Measurements in the wind tunnel

\section{Figure 4}

Typical examples of recorded data for the lift and drag forces

Figure 5

Experimental results of lift $\left(C_{l}\right)$ and $\operatorname{drag}\left(C_{d}\right)$ coefficients

\section{Supplementary Files}


This is a list of supplementary files associated with this preprint. Click to download.

- graphicalabstract.docx

- appendices.pdf 